\title{
Outcomes of dental implants in young patients with congenital versus non- congenital missing teeth
}

\author{
Yousef Al Najam@, Ali Tahmaseb, Dorothee Wiryasaputra, Eppo Wolvius and Brunilda Dhamo*
}

\begin{abstract}
Objective: This cross-sectional study aims to investigate the effect of the cause of missing teeth on the survival and subjective success of dental implant treatment (DIT) in young patients with missing teeth due to non-congenital causes (tooth loss) in comparison to patients with missing teeth because of congenital causes (hypodontia and oligodontia).
\end{abstract}

Material and methods: All patients were asked 7 questions to extract information about the survival and subjective success of DIT. Implant survival function was designed using the Kaplan-Meier analysis. Differences in implant success outcomes were studied using binary logistic regression analysis.

Results: One hundred ten patients aged 18 to 40 years old were included, whereof 32 patients with tooth loss, 25 patients with hypodontia and 53 patients with oligodontia. In the tooth loss group, implant survival reached 96.9\%; in the hypodontia group 96.0\%; and in the oligodontia group $88.7 \%$. Regarding subjective implant success, patient satisfaction was significantly higher $(p<0.040)$ among patients with congenital missing teeth in comparison to patients with tooth loss. Other implant success components showed no statistically significant difference $(p>0.050)$ between the groups.

Conclusion: The cause of missing teeth does not influence implant survival. However, the cause of missing teeth does have a significant impact on patient satisfaction (implant success), ascertaining young patients with congenital missing teeth as more satisfied of DIT than young patients with tooth loss.

Clinical relevance: Young patients with tooth agenesis and with an increased number of missing teeth are more content about the treatment with dental implants than patients with tooth loss. Furthermore, a consensus regarding the assessment of implant success is an essential concern for clarification.

Keywords: Tooth, Agenesis, Non-congenital, Implant, Success, Survival

\section{Introduction}

Tooth agenesis is defined as the congenital absence of one or more missing teeth excluding the third molars [37]. Tooth agenesis is the most common congenital dental abnormality with a prevalence that varies between $0.15 \%$ and $16.2 \%$ in different study populations [32]. Based on the number of missing teeth, tooth agenesis is

\footnotetext{
* Correspondence: b.dhamo@erasmusmc.nl

Department of Oral and Maxillofacial Surgery, Erasmus University Medical Center Rotterdam, PO Box 2040, CA 3000 Rotterdam, the Netherlands
}

classified in hypodontia (1-5 missing teeth), oligodontia (6-27 missing teeth), and anodontia (28 missing teeth) [36]. Non-congenitally absence of teeth, known as tooth loss, can be presented as partial or total edentulism. Edentulism is a major public health problem affecting $6-80 \%$ of the people in different countries $[12,22]$. Tooth loss occurs as a result of severe dental caries, trauma, and pathogenic mobility due to severe periodontitis [33]. In order to bring back the functionality and aesthetics of the dentition to the patients with missing 
teeth, a multidisciplinary team of dentists, orthodontists, maxillofacial surgeons, and psychologists is needed [14].

Dental implant treatment (DIT) is recognized as the most successful treatment for missing teeth because of the high survival rate of more than $94.0 \%$ over a mean period of 13 years [16, 29]. However, several factors such as smoking, unhealthy/sugary diet, bruxism, xerostomia, osteoporosis, diabetes, and radiotherapy can contribute to unsatisfactory outcomes and very early failure of the implants in patients with missing teeth due to congenital or non-congenital causes [34]. A systematic review of the literature has shown that the mean implant survival in patients with oligodontia is $93.7 \%$, varying from 35.7 to $98.7 \%$ over a period of 18 years [14]. The variance of 35.7 to $98.7 \%$ is explained by the inclusion of studies performed in children $(<15$ years old) with lower bone quantity and thus a higher risk for DIT failure rate. In another study, patients with hypodontia and oligodontia showed high satisfaction and masticatory function (69.4\%), high phonetic ability (80.6\%), and high implant success (88.4\%) according to Albrektsson criteria [3].

Studies about DIT in patients with missing teeth due to non-congenital causes such as severe periodontitis have reported higher survival rates between $97 \%$ and $100 \%$ in short-term follow-up period of 2 to 8 years [7, $23,25,26]$. Long-term follow-up investigations have resulted in survival rates between $83 \%$ and $96 \%$ after 10 years [7, 20, 21, 23-26]. Accordingly, the follow-up time is an important determinant for the DIT survival. Another study which examined the implant success in patients with tooth loss has reported success rates between $38.5 \%$ and $77.9 \%$ over a period of 3 to 6 years [27].

Based on the reported values, outcomes of DIT in patients with congenital missing teeth might be less favorable compared to outcomes in a group of patients with tooth loss due to caries, infection, or trauma. However, due to a lack of comparative studies, the question whether the outcomes of DIT in patients with congenital missing teeth differ from patients with tooth loss remains unraveled. Therefore, the aim of this research is to study the effect of the cause of missing teeth on the survival and subjective success of DIT in patients with missing teeth due to non-congenital causes (tooth loss) in comparison to patients missing teeth because of congenital causes (hypodontia and oligodontia).

\section{Material and methods}

\section{Study design and study population}

In this cross-sectional study, inclusion criteria were (1) patients who were diagnosed with tooth loss or tooth agenesis (hypodontia or oligodontia); (2) patients who were examined and treated with dental implants since 2006 at the Department of Oral \& Maxillofacial Surgery of Erasmus Medical Center in Rotterdam, the
Netherlands; (3) patients between 18 and 40 years old. As shown in the literature, a higher age is associated with a higher risk of implant loss [30,31], this study only included patients of age $<40$ years old in order to minimize the confounding effect of age on the clinical outcomes of DIT as much as possible. In total, 1054 patients were evaluated for the eligibility to participate in the study (Fig. 1). The following exclusion criteria were considered: (1) patients older than 40 years old $(N=$ $479)$ and younger than 18 years old $(N=150)$; (2) presence of systemic diseases and history of head and neck radiotherapy $(N=150)$; (3) syndromic tooth agenesis (e.g., ectodermal dysplasia, clefts; $N=137$ ); (4) patients with no contact records available or who were unreachable $(N=28)$. Therefore, the final study population consisted of 110 patients, of which 32 patients were diagnosed with tooth loss, 25 patients had hypodontia, and 53 patients were diagnosed with oligodontia. The medical records and dental panoramic radiographs (DPRs) of the patients were evaluated by an independent and trained examiner (Y. A.N.) from October until end of November 2018. The utilization of DPRs was performed in accordance with the general treatment protocol. The general information of the patients was used in strict compliance with the patient privacy regulation of the Erasmus Medical Center and consent of the patients. The study was conducted in accordance with the Declaration of Helsinki and was approved by the Medical Ethics Committee of the Erasmus Medical Center in Rotterdam, the Netherlands (MEC-2020-0301).

\section{Exposure assessment: the cause of missing teeth}

Missing teeth were assessed during the clinical examination by dental professionals and were in addition determined in the DPRs or medical records of the patients. A tooth was classified as congenitally missing when no sign of formation or calcification was shown in the DPR taken between the ages of 6 and 15 years. Patients with 1 or more congenitally missing teeth, excluding third molars, were diagnosed with tooth agenesis and composed the group of patients with missing teeth due to congenital causes classified into the hypodontia (1-5 missing teeth) and oligodontia (6-27 missing teeth) group $[1,35]$. Finally, patients who had a history of tooth extractions or tooth loss because of severe periodontitis, severe caries or dental trauma, were included in the group of patients with tooth loss. Patients with tooth loss were assigned as the reference group of the study.

\section{Surgical protocol}

The surgical procedures were performed under local or general anesthesia. The position of the dental implant was determined by preoperative radiological measurements, dental setup, and surgical guide. Bone level 
Patients who were treated with dental implants at the Department of Oral \& Maxillofacial Surgery of Erasmus Medical Center Rotterdam $\mathbf{n}=\mathbf{1 . 0 5 4}$

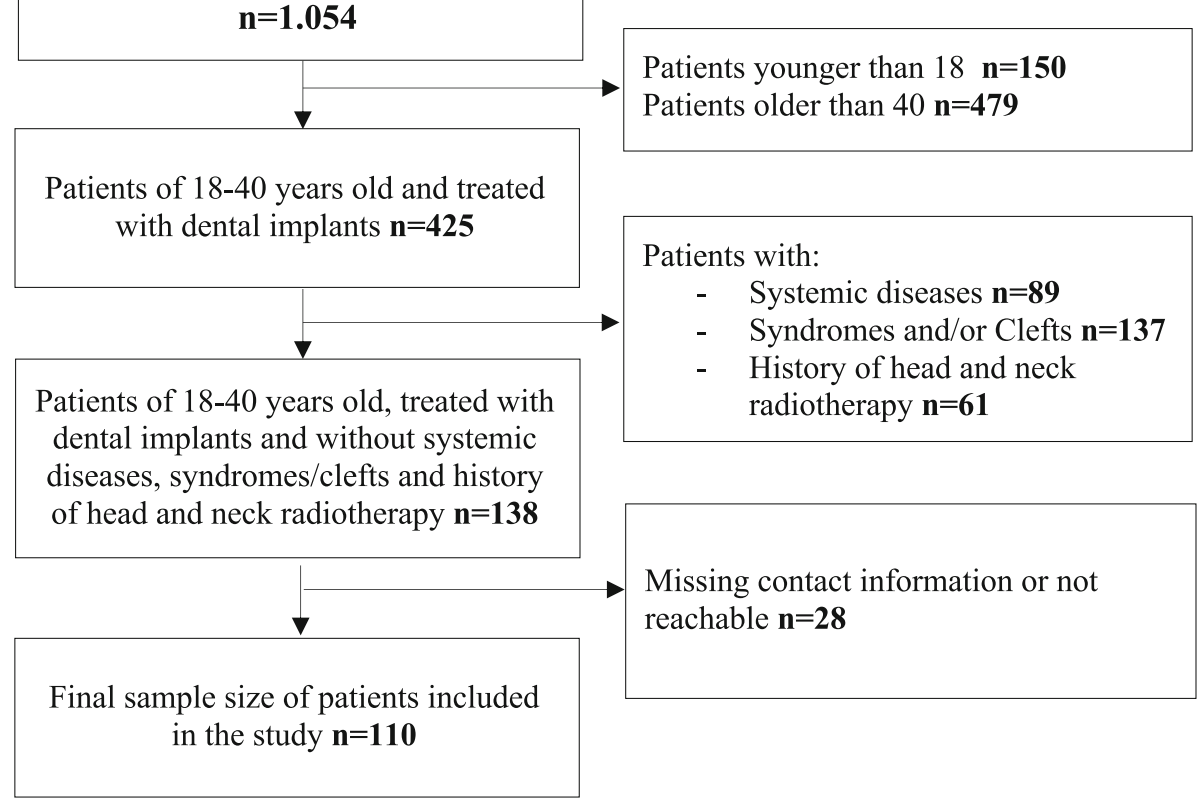

Fig. 1 Flowchart of the study population

implants with 3.3 and $4.1 \mathrm{~mm}$ diameter (Straumann ${ }^{\circ}$ Bone Level, Basel, Switzerland) were inserted. Bone augmentation was performed in patients with insufficient bone volume, either as a separate pre-implantological procedure (4 months prior to implant placement) or at implant placement in case of relatively small defects with titanium dehiscence of less than $4 \mathrm{~mm}$. The bone was harvested either from the ascending ramus or extraorally from either the outer skull or the iliac crest. In addition, alloplastic material (Straumann Cerabone) was used in a mix with autogenous bone chips. In general, implant placement was performed in two stages with a period of 4 months in between [19].

\section{Assessment of implant outcomes: implant survival and subjective implant success Implant survival}

The primary outcome variable is the survival time of implants (years) and is defined as the time difference between the moment of the last contact/visit or implant loss and the date of first implantation. Implant loss is defined as failure of osseointegration.

\section{Subjective implant success}

The secondary outcome variable is the subjective implant success rate and is defined based on seven important implant outcomes (Table 1): (1) absence of mobility,
(2) lack of persistent subjective complaints, (3) absence of recurrent peri-implantitis with suppuration, (4) absence of a continuous radiolucency around the implant, (5) pocket probing depth (PPD) not higher than $5 \mathrm{~mm}$, (6) no bleeding on probing (BOP), and (7) minimal bone resorption (less than $1.5 \mathrm{~mm}$ ) observed in X-ray image [11].

In impossibility to achieve a control visit for all the patients and measure the objective and subjective implant outcomes, implant outcomes were recorded from an individual Dutch questionnaire with seven closed ('yes' or 'no') questions derived from the above-mentioned criteria. The eligible patients were reached by e-mail or phone. Patients were asked whether they (1) had lost the implant(s), (2) had noticed mobility of the suprastructure(s), (3) had complaints related to the implant(s), (4) were functionally and esthetically satisfied with the implant(s), (5) visited the dentist on a regular basis (twice a year) since the implant(s) was (were) placed, (6) had experienced recurrent infections around the implant(s) noticed by the dentist or oral hygienist, and (7) had noticed bleeding gums around the implant(s) while toothbrushing or cleaning interdentally. Dichotomized variables on implant outcomes were created from the patients' answers and were used as dependent variables in the following statistical analysis. 
Table 1 Criteria used to measure success rate of dental implants

\begin{tabular}{|c|c|c|}
\hline Criterion & Used & Question asked \\
\hline Absence of mobility [6] & Yes & Are the implants mobile? \\
\hline $\begin{array}{l}\text { Absence of persistent subjective complaints (pain, foreign body sensation and/or } \\
\text { dysesthesia) [6] }\end{array}$ & Yes & $\begin{array}{l}\text { Do you have any complaints in regard to the } \\
\text { implants? Are you satisfied with the implants? }\end{array}$ \\
\hline Absence of recurrent peri-implant infection with suppuration [6] & Yes & $\begin{array}{l}\text { Are there any recurrent infections noticed by your } \\
\text { dentist or oral hygienist? }\end{array}$ \\
\hline Absence of a continuous radiolucency around the implant [6] & No & - \\
\hline No pocket probing depth (PPD) $>5 \mathrm{~mm}[5,28]$ & Yes & $\begin{array}{l}\text { Is there any bleeding noticed when brushing or } \\
\text { cleaning interdentally? }\end{array}$ \\
\hline No PPD $\geq 5 \mathrm{~mm}$ and bleeding on probing (BOP) [28] & Yes & $\begin{array}{l}\text { Is there any bleeding noticed when brushing or } \\
\text { cleaning interdentally? }\end{array}$ \\
\hline $\begin{array}{l}\text { During the first year, a 1.5-mm vertical bone resorption was accepted. After the first } \\
\text { year of service, the annual vertical bone loss should not exceed } 0.2 \mathrm{~mm} \text { (mesially or } \\
\text { distally) ([2], Albrektsson and Isidor 1994) }\end{array}$ & No & - \\
\hline
\end{tabular}

\section{Covariates}

Information about general characteristics such as age, sex, ethnicity, and smoking were extracted from the clinical patient database (Chipsoft Healthcare Information $\mathrm{X}$-change (HiX) program). Information about surgical treatment and treatment characteristics such as date of first implantation, number of dental implants, implant loss, number of missing teeth, need for bone augmentation, type of bone graft, morbidity, and additional surgical interventions was also collected from the patient medical records using HiX program.

\section{Statistical analyses}

The study population was characterized using descriptive statistics. Differences in general characteristics and implant outcomes among patients with hypodontia, oligodontia, and tooth loss (reference group) were evaluated using Mann-Whitney non-parametric test for continuous variables with a skewed distribution and chisquared test for categorical variables. Implant survival function was presented using the Kaplan-Meier analysis considering the implant loss events during the follow-up period. Log-rank tests were used to analyze differences in survival rates between the subgroups (hypodontia vs. tooth loss and oligodontia vs tooth loss). Differences in implant outcomes (implant loss, satisfaction, complaints, mobility, bleeding, and recurrent infections) between patients with tooth loss and patients with missing teeth due to congenital causes (hypodontia and oligodontia) were studied using binary logistic regression analysis, from which OR (odds ratios) and 95\% CI were obtained from two consecutive models. In both models, the cause of missing teeth is considered as the main determinant and implant loss, patient satisfaction, complaints, implant mobility, bleeding, and recurrent infections as the primary outcomes. In model 1, the confounding effects of age, sex, smoking and number of missing teeth were taken into consideration. Subsequently, model 2 was additionally adjusted for bone augmentation and accompanying surgical procedures involving the craniofacial structures. The covariates were included in the logistic regression models based on previous literature or a change of $>10 \%$ in effect estimates. For all analyses, statistical significance was reached for $\mathrm{p}$ value $<0.05$. All statistical analyses were performed using statistical package for social sciences SPSS version 24.0. At last, this study is in compliance with the STROBE checklist (Supplementary Table 1).

\section{Results}

\section{Subject characteristics}

The baseline characteristics of the study population are shown in Table 2.

Patients included in the study were followed up for a median time of 3.6 years $(90 \% \mathrm{CI}, 0.4-10.2$ years). The mean follow-up of patients in the oligodontia group was 4.3 years (95\% CI, 3.5-5.1 years), in the hypodontia group 3.1 years (95\% CI, 2.1-4.1 years), and in the tooth loss group 4.4 years (95\% CI, 3.1-5.6 years). No statistically significant differences in both median and mean follow-up period were observed in patients with hypodontia and oligodontia compared to patients with tooth loss. A significantly higher number of maxillary and mandibular teeth were missing in patients with oligodontia (median $=9$ teeth; $90 \%$ range, 6-18 teeth) than in patients with tooth loss (median $=3$ teeth; $90 \%$ range, 1-10 teeth). In consequence, more implants per patient (maxilla $p<0.001$; mandible $p=0.004$ ) and more implants overall (maxilla $p=0.002$; mandible $p=0.013$ ) were placed in the oligodontia group than in the reference group. Compared to the patients with tooth loss, the patients with hypodontia showed no statistically significant difference in the number of missing teeth ( $\mathrm{p}=$ $0.855)$ and the number of placed implants $(\mathrm{p}=0.234)$. In comparison with the reference group, the hypodontia group had significantly younger participants $(p=0.007)$ 
Table 2 Baseline characteristics of the study population

\begin{tabular}{|c|c|c|c|c|c|}
\hline & ${ }^{*}$ Non-congenital missing teeth $(N=32)$ & Hypodontia $(N=25)$ & $p$ value & Oligodontia $(N=53)$ & $p$ value \\
\hline \multicolumn{6}{|l|}{ General characteristics } \\
\hline Age (years) & $26.0(21.7-38.0)$ & $23.0(18.3-27.7)$ & 0.007 & $25.0(19.4-29.6)$ & 0.700 \\
\hline $\operatorname{Sex}(N, \%)$ & & & 0.047 & & 0.983 \\
\hline Males & $20(62.5)$ & $9(36.0)$ & & $33(62.3)$ & \\
\hline Females & $12(37.5)$ & $16(64.0)$ & & $20(37.7)$ & \\
\hline Ethnicity (N, \%) & & & 0.680 & & 0.144 \\
\hline Caucasians & $26(81.3)$ & $22(88.0)$ & & $48(90.6)$ & \\
\hline Africans & $5(15.6)$ & $2(8.0)$ & & $2(3.8)$ & \\
\hline Asian & $1(3.1)$ & $1(4.0)$ & & $3(5.7)$ & \\
\hline Smoking (N, \%) & & & 0.056 & & 0.146 \\
\hline Yes & $9(28.1)$ & $2(8.0)$ & & $8(15.1)$ & \\
\hline No & $23(71.9)$ & $23(92.0)$ & & $45(84.9)$ & \\
\hline Missing teeth & $3(1-10)$ & $3(1-5)$ & 0.855 & $9(6-18)$ & $<0.001$ \\
\hline Maxilla & $2(0-7)$ & $2(0-5)$ & 0.879 & $5(2-8)$ & $<0.001$ \\
\hline Mandible & $1(0-7)$ & $1(0-4)$ & 0.879 & $4(1-10)$ & 0.002 \\
\hline Missing teeth overall $(\mathrm{N}, \%)$ & & & 0.517 & & $<0.001$ \\
\hline Maxilla & $66(55.5)$ & $48(64.0)$ & 0.909 & $287(53.5)$ & $<0.001$ \\
\hline Mandible & $54(45.0)$ & $27(36.0)$ & 0.798 & $249(46.5)$ & $<0.001$ \\
\hline \multicolumn{6}{|l|}{ Placed implants per patient } \\
\hline Maxilla & $2(1-4)$ & $1(0-5)$ & 0.855 & $3(1-5)$ & $<0.001$ \\
\hline Mandible & $0(0-4)$ & $1(0-3)$ & 0.907 & $3(0-6)$ & 0.004 \\
\hline \multicolumn{6}{|l|}{ Placed implants overall (N, \%) } \\
\hline Maxilla & $51(60.7)$ & $35(63.6)$ & 0.928 & $165(54.5)$ & 0.002 \\
\hline Mandible & $33(39.3)$ & $20(36.4)$ & 0.325 & $138(45.5)$ & 0.013 \\
\hline Type of bone graft $(\mathrm{N}, \%)$ & & & 0.234 & & 0.319 \\
\hline Ascending ramus & $18(36.7)$ & $13(52.0)$ & & $28(52.8)$ & \\
\hline Extra-oral & $4(8.2)$ & $0(0.0)$ & & $8(15.1)$ & \\
\hline Skull & 1 & - & & 3 & \\
\hline Iliac crest & 3 & - & & 5 & \\
\hline Alloplastic & $1(2.0)$ & $1(4.0)$ & & $0(0.0)$ & \\
\hline No bone augmentation & $26(53.1)$ & $11(44.0)$ & & $17(32.1)$ & \\
\hline Additional procedures (N, \%) & & & 0.650 & & 0.176 \\
\hline $\mathrm{BSSO}$ & $5(15.6)$ & $2(8.0)$ & & $3(5.7)$ & \\
\hline SARME/Bimax & $2(6.2)$ & $1(4.0)$ & & $13(24.5)$ & \\
\hline Other surgical procedures & $0(0.0)$ & $0(0.0)$ & & $3(5.7)$ & \\
\hline No surgical procedures & $25(78.1)$ & $22(88.0)$ & & $34(64.2)$ & \\
\hline Regular visits at the dentist (N, \%) & & & 0.217 & & 0.053 \\
\hline Yes & $24(75.0)$ & $22(88.0)$ & & $48(90.6)$ & \\
\hline No & $8(25.0)$ & $3(12.0)$ & & $5(9.4)$ & \\
\hline \multicolumn{6}{|l|}{ Implants outcomes } \\
\hline Follow-up time (years; median) & $3.3(0.6-12.5)$ & $2.7(0.2-9.0)$ & 0.342 & $4.2(0.3-9.9)$ & 0.301 \\
\hline Follow-up time (years; mean) & $4.4(3.1-5.6)$ & $3.1(2.1-4.1)$ & 0.106 & $4.3(3.5-5.1)$ & 0.902 \\
\hline \multicolumn{6}{|l|}{ Lost implants (N, \%) } \\
\hline Maxilla & $0(0.0)$ & $2(5.7)$ & 0.254 & $3(1.8)$ & 0.171 \\
\hline
\end{tabular}


Table 2 Baseline characteristics of the study population (Continued)

\begin{tabular}{|c|c|c|c|c|c|}
\hline & ${ }^{*}$ Non-congenital missing teeth $(N=32)$ & Hypodontia $(N=25)$ & $p$ value & Oligodontia $(N=53)$ & $p$ value \\
\hline Mandible & $1(3.0)$ & $0(0.0)$ & 0.373 & $3(2.2)$ & 0.593 \\
\hline Satisfaction (N, \%) & & & 0.039 & & 0.044 \\
\hline Yes & $27(84.4)$ & $25(100.0)$ & & $51(96.2)$ & \\
\hline No & $5(15.6)$ & $0(0.0)$ & & $1(1.9)$ & \\
\hline N/A & $0(0.0)$ & $0(0.0)$ & & $1(1.9)$ & \\
\hline Complaints (N, \%) & & & 0.706 & & 0.408 \\
\hline Yes & $4(12.5)$ & $4(16)$ & & $3(5.7)$ & \\
\hline No & $28(87.5)$ & $21(84)$ & & $49(92.5)$ & \\
\hline N/A & $0(0.0)$ & $0(0.0)$ & & $1(1.9)$ & \\
\hline Mobility (N, \%) & & & 0.203 & & 0.714 \\
\hline Yes & $2(6.3)$ & $0(0.0)$ & & $4(7.5)$ & \\
\hline No & $30(93.8)$ & $25(100)$ & & $48(90.6)$ & \\
\hline N/A & $0(0.0)$ & $0(0.0)$ & & $1(1.9)$ & \\
\hline Bleeding (N, \%) & & & 0.452 & & 0.645 \\
\hline Yes & $16(50.0)$ & $10(40.0)$ & & $29(54.7)$ & \\
\hline No & $16(50.0)$ & $15(60.0)$ & & $23(43.4)$ & \\
\hline N/A & $0(0.0)$ & $0(0.0)$ & & $1(1.9)$ & \\
\hline Recurrent infections ( $\mathrm{N}, \%)$ & & & 0.479 & & 0.460 \\
\hline Yes & $9(28.1)$ & $5(20.0)$ & & $20(37.7)$ & \\
\hline No & $23(71.9)$ & $20(80.0)$ & & $32(60.4)$ & \\
\hline N/A & $0(0.0)$ & $0(0.0)$ & & $1(1.9)$ & \\
\hline
\end{tabular}

Footnote: *- reference group, $N$ number of participants

Values are numbers and percentages for categorical variables or medians (90\% range) for ordinal and continuous variables with a skewed distribution Follow-up time is presented as median $(90 \% \mathrm{Cl})$ and mean $(95 \% \mathrm{Cl})$. Differences were tested using the Mann-Whitney $\mathrm{U}$ non-parametric test for continuous variables and chi-squared test for categorical variables; $p<0.05$ is considered statistically significant and presented in italics

and more female participants $(p=0.047)$. No statistically significant differences in ethnicity, smoking, bone augmentation, additional procedures, and regular visits at the dentist after DIT were shown in the hypodontia and oligodontia groups compared with the tooth loss group ( $\mathrm{p}>0.05)$.

\section{The cause of missing teeth and implant survival}

One implant out of 84 had failed osseointegration in patients with tooth loss, providing a cumulative survival rate of $96.9 \%$ (mean survival $=13.27$ years; $95 \% \mathrm{CI}$ $12.46,14.08$ years). Two implants out of 55 were lost in patients with hypodontia, resulting in a cumulative survival rate of $96.0 \%$ (mean survival $=8.94$ years; $95 \% \mathrm{CI}$ 8.19, 9.70 years). Six implants out of 303 had failed in patients with oligodontia, resulting in a cumulative survival of $88.7 \%$ (mean survival $=10.50$ years; $95 \%$ CI 9.40, 11.60 years) (Fig. 2). The log-rank test showed no statistically significant difference in the survival rate of implants among the groups of oligodontia vs. hypodontia $(\mathrm{p}=0.425)$, oligodontia vs. tooth loss $(\mathrm{p}=0.210)$ and hypodontia vs. tooth loss $(\mathrm{p}=0.785)$. The median survival time of the failed implants was 1.3 years in the oligodontia group, 0.3 years in the hypodontia group, and 0.7 years in the tooth loss group.

\section{The cause of missing teeth and subjective implant success}

As shown in Table 3 and Fig. 3 the cause of missing teeth (congenital vs non-congenital) was not statistically significantly associated with failure of osseointegration, complaints, mobility, bleeding, and peri-implantitis, when considering for potential confounders in both models 1 and 2 . In model 1 , patients with congenitally missing teeth (hypodontia and oligodontia) were significantly more satisfied with the dental implants compared to patients with tooth loss $(\mathrm{OR}=19.71,95 \%$ CI 1.33 , 292.19). Patient satisfaction remained significantly higher $(p<0.040)$ in patients with congenital missing teeth in model 2; however, the effect estimate decreased (OR = 18.18, 95\% CI 1.14, 289.15) (Fig. 3).

\section{Discussion}

Findings from this cross-sectional study with retrospective measurement of exposure, suggest that the cause of missing teeth does not influence implant survival. 


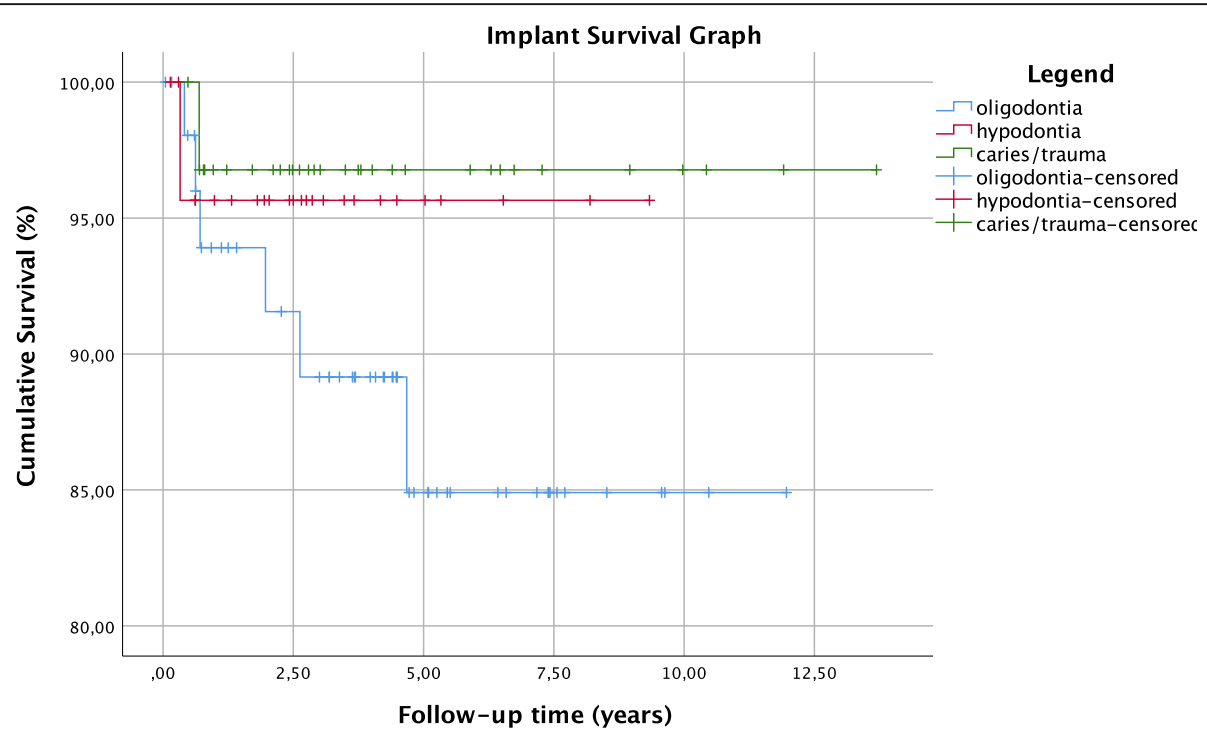

Fig. 2 Presentation of the implant survival function. Footnote: the non-congenital tooth loss group of patients showed a cumulative implant survival rate of $96.9 \%$ (mean survival $=13.27$ years; $95 \% \mathrm{Cl} 12.46,14.08$ years), the hypodontia group showed a cumulative implant survival rate of $96.0 \%$ (mean survival $=8.94$ years; $95 \% \mathrm{Cl} 8.19,9.70$ years) and the oligodontia group showed a cumulative implant survival rate of $88.7 \%$ (mean survival $=10.50$ years; $95 \% \mathrm{Cl} 9.40,11.60$ years)

Furthermore, the cause of missing teeth has no significant impact on implant success components naming failure of osseointegration, complaints, implant mobility, bleeding, and peri-implantitis. Interestingly, the only component of implant success influenced by the cause of missing teeth is patient satisfaction. Young patients with congenitally missing teeth are significantly more satisfied with their implants compared to patients with missing teeth due to caries, periodontitis or trauma.

\section{Interpretation of the main findings}

The evaluation of the cause of missing teeth as an indicator of implant survival and success is unraveled in the literature. In this study, the relationship between cause of missing teeth and implant outcomes was hypothesized based on existing evidence about decreased bone quantity and quality in patients with congenital missing teeth
[32]. In addition, tooth agenesis indicates often aberrant occlusal traits mentioning the tendency towards class III malocclusion, which can highly influence the longevity of dental implants in jaws [8]. Based on these facts, a lower survival and success rate of implants in patients with congenital missing teeth was expected, but not shown in the findings of our study.

\section{Implant survival}

Literature has shown lower implant survival rates in patients with congenitally missing teeth in comparison to patients with tooth loss $[7,14,20,21,23-26]$. In a short-term follow-up period, comparative results were found, showing a cumulative survival rate of $96.9 \%$ for patients with tooth loss, $96.0 \%$ for patients with hypodontia, and $88.7 \%$ for patients with oligodontia. Although, a statistically significant difference in DIT

Table 3 Association between the cause of missing teeth and implants outcomes

\begin{tabular}{|c|c|c|c|c|c|c|}
\hline \multirow{2}{*}{$\begin{array}{l}\text { Congenital vs non- } \\
\text { congenital causes }\end{array}$} & \multicolumn{3}{|c|}{ Model 1} & \multicolumn{3}{|c|}{ Model 2} \\
\hline & OR & $95 \% \mathrm{Cl}$ & $p$ value & OR & $95 \% \mathrm{Cl}$ & $p$ value \\
\hline Implant loss & 5.25 & $0.25,108.33$ & 0.283 & 4.17 & $0.24,71.72$ & 0.326 \\
\hline Satisfaction & 19.71 & $1.33,292.19$ & $0.030^{*}$ & 18.18 & $1.14,289.15$ & $0.040^{*}$ \\
\hline Complaints & 0.55 & $0.12,2.49$ & 0.435 & 0.70 & $0.14,3.49$ & 0.667 \\
\hline Mobility & 0.84 & $0.07,9.48$ & 0.886 & 0.88 & $0.08,9.21$ & 0.912 \\
\hline Bleeding & 1.12 & $0.40,3.18$ & 0.827 & 1.07 & $0.37,3.07$ & 0.905 \\
\hline Recurrent inflammations & 1.43 & $0.44,4.70$ & 0.555 & 1.47 & $0.45,4.88$ & 0.525 \\
\hline
\end{tabular}

Footnote: $O R$ odds ratio; *statistically significant $\mathrm{p}$ values are presented in italics

Model 1 was adjusted for age, sex, smoking (yes or no), and number of missing teeth (continuous)

Model 2 was additionally adjusted for bone augmentation (yes or no) and additional surgical procedures involving craniofacial structures (yes or no) 


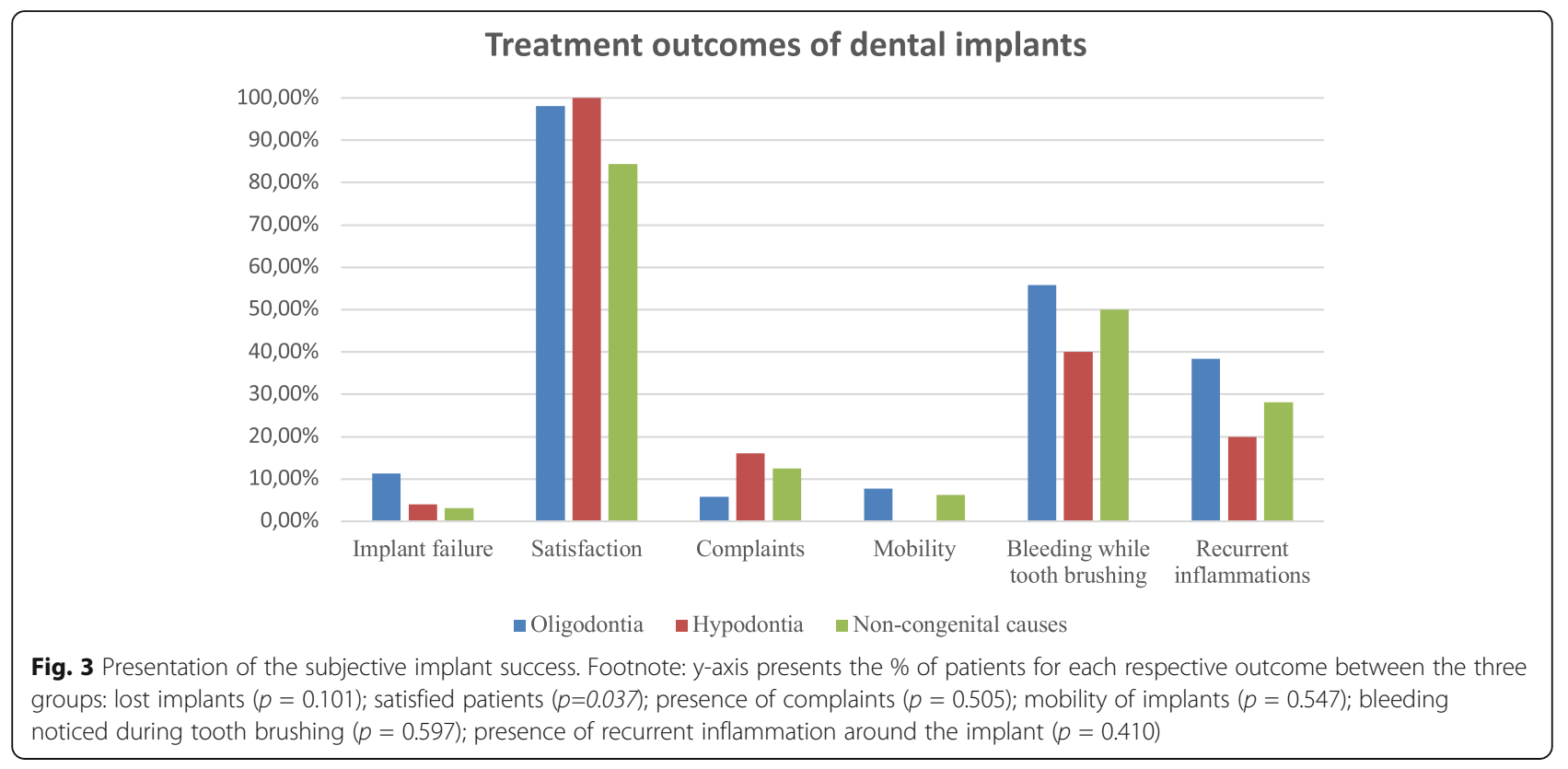

survival could not be proved, a deceleration trend of implant survival was observed in ascending order in patients with tooth loss, hypodontia, and oligodontia. Furthermore, the implant survival tends to decelerate with the increase in number of missing teeth. Patients with oligodontia are characterized by more missing teeth in comparison to patients with hypodontia or patients with tooth loss. More missing teeth are accompanied by the need of placing more implants to recover the function of the dentition. On the other hand, more missing teeth are implicated in the decrease of cortical bone density, which thoroughly compromises the survival and the success of dental implants [32].

\section{Subjective implant success}

Literature has reported lower implant success rates regarding DIT in patients with tooth loss, in comparison to patients with congenital missing teeth [27]. Most of the studies on dental implants use the term success rate synonymously with the term survival rate, which leads to biased interpretation and overestimations of success rates, which are usually lower than the survival rate of implants. Therefore, difficulties were faced in selecting reported values in the literature for the interpretation of our findings about the subjective implant success based on the DIT outcomes (including patient satisfaction, complaints, implant mobility, bleeding, and recurrent inflammations). The systematic review of Filius et al. reported very high satisfaction rates $(>85 \%)$ for DIT in patients diagnosed with hypodontia and oligodontia [14]. Topcu et al. studied satisfaction of patients diagnosed with tooth loss and reported a satisfaction rate of $87.4 \%$ (varying from $71 \%$ to $99 \%$ ) [38]. In line with these results, significantly high satisfaction rates of patients with hypodontia (100\%) and patients with oligodontia (98\%) were demonstrated, compared to patients with tooth loss (84.4\%). Topcu et al. reported that improved satisfaction is related to improved esthetics and function in comparison to the old oral state [38]. In general, patients with congenital missing teeth undergo a long and intense dental treatment of several disciplines, restorative dentistry, orthodontics, prosthodontics, and oral and maxillofacial surgery. This group of patients tend to compare the function and esthetics of the current dentition restored by dental implants with the past status of the dentition predominated by unaccomplished esthetics due to absence of several teeth and presence of malformed teeth. Therefore, patients with tooth agenesis are prone to feel more satisfied with their implants since the improvement of function and esthetics of their dentition is highlighted after restoration. Whereas, patients with tooth loss are likely to feel less satisfied with dental implants, because they tend to compare the current status of the dentition with their past complete and healthy dentition, prior experiencing tooth loss due to caries, periodontitis and trauma.

Further, Lima et al. reported that patient's expectation prior to DIT is an important factor for the patient satisfaction of DIT [10]. As stated before, patients who are diagnosed with tooth agenesis follow long and intense treatments being in continuous contact with the clinicians from the moment of diagnoses. Meanwhile, patients with tooth loss are in general less frequently in contact with the clinicians. Therefore, patients with tooth agenesis have a clearer perception of their situation and a more realistic expectation of DIT, which also 
contributes to a higher patient satisfaction of DIT of patients with tooth agenesis.

Previous literature reported that in patients with oligodontia the bleeding on probing (BoP) rate is 32\% [17]. Farina et al. reported BoP rates of $27 \%$ around implants of patients with tooth loss [13]. In this study, bleeding and recurrent inflammations tended to occur more frequently in patients with oligodontia $(55.8 \%$ and $38.5 \%$ respectively) than in patients with hypodontia (40.0\% and $20.0 \%$, respectively) or in patients with tooth loss (50\% and $28.1 \%$ ). However, no statistical significance could be proven on the effect of the cause of missing teeth on the subjective success of implants considering bleeding and recurrent inflammations.

\section{Strengths and limitations}

For the interpretation of the study results, some strengths and limitations have to be considered.

As the cause of missing teeth has not been previously considered as a determinant of implant outcomes, the findings of this study add knowledge to the current literature about the factors that influence implant survival and success. The cause of missing teeth was evaluated as an indicator of implant outcomes by providing scientific evidence from a clinical retrospective observation. One of the strengths of the current study is the emphasis given to the subjective evaluation of satisfaction and complaints as implant outcomes. Both representing important components of implant success which are often overshadowed in the literature by the high reported survival rates $[4,7,9,15,18,25,39]$. The population size in the present study was relatively small which leads to decreased statistical power and might also have affected the significance of the effect estimates and $p$ values. The retrospective nature of the study design counts as another limitation because it can generate selection and recall bias. Consequently, the control on the outcome assessment might have been affected. In addition, retrospective designs require very large sample sizes to study such rare outcomes. Therefore, it is important to underline the need of a large-scale dataset and a long term follow-up to assess implant survival and success for the performance of future studies. Tooth agenesis, however, can be considered as a rare congenital dental anomaly and quite challenging to achieve large sample size for the study population.

Bleeding and recurrent inflammations were assessed subjectively by asking the patients questions via call or mail. Although inapplicable for the current study, the best way to assess bleeding and recurrent inflammations would be to continuously follow-up the patients by organizing control examinations. Moreover, radiolucency around the implant and annual peri-implant bone loss $(\leq$ $0.2 \mathrm{~mm}$ ) 1 year after insertion of the superstructure [11] was not assessed because in most of the cases a recent radiograph was not present. The criteria of Donos et al. were applied to define implant success, because the criteria included by the authors considered all implant success definitions of each study included in their systematic review [11]. However, a lack of consensus or clear definition of implant success is present in the literature. There is a high need for a unified score system where patient satisfaction and implant survival are combined to define implant success rate.

In conclusion, the cause of missing teeth does not affect the short-term survival of dental implants but it does indicate the subjective implant success from the perspective of patient satisfaction. Patients with tooth agenesis and with an increased number of missing teeth are more content about the treatment with dental implants than patients with tooth loss. A consensus in the literature regarding the assessment of implant success is an essential concern for clarification by future research.

\section{Abbreviations}

DIT: Dental implant treatment; DPR: Dental panoramic radiographs; HiX: Chipsoft Healthcare Information X-change program; PPD: Pocket probing depth; OR: Odds ratio; Cl: Confidence interval

\section{Supplementary Information}

The online version contains supplementary material available at https://doi. org/10.1186/s40729-021-00362-7.

Additional file 1: Supplementary Table 1. STROBE Statement.

\section{Acknowledgements}

The authors thank colleagues in the Department of Oral \& Maxillofacial Surgery at Erasmus University Medical Centre for the referral of the patients. We gratefully acknowledge the contribution of all participating patients. There was no funding received for this study.

Authors' contributions

YAN, DW, EBW, and BD conceived the ideas; EBW, DW, and BD contributed to data acquisition; YAN performed data-collection; YAN and BD performed data-analysis: YAN, EBW, and BD contributed to the interpretation of data and writing of the manuscript; $A T, E B W$, and $B D$ revised the manuscript critically; YAN, AT, EBW, and BD drafted the final manuscript. All authors read and approved the final manuscript.

\section{Funding}

The work was supported by the Department of Oral \& Maxillofacial Surgery, Special Dental Care and Orthodontics of Erasmus Medical Centre in Rotterdam, the Netherlands.

Availability of data and materials

Supporting data is available.

\section{Declarations}

Ethics approval consent to participate

All procedures performed in studies involving human participants were in accordance with the ethical standards of the institutional and national research committee and with the 1964 Helsinki declaration and its later amendments or comparable ethical standards. Informed consent was obtained from all individual participants included in the study.

Consent for publication

Informed consent was obtained for publication. 


\section{Competing interests}

Author YAN declares that he has no conflict of interest. Author AT declares that he has no conflict of interest. Author DW declares that she has no conflict of interest. Author EBW declares that he has no conflict of interest. Author BD declares that she has no conflict of interest.

Received: 16 March 2021 Accepted: 28 May 2021

Published online: 23 August 2021

\section{References}

1. Al-Ani AH, Antoun JS, Thomson WM, Merriman TR, Farella M. Hypodontia: an update on its etiology, classification, and clinical management. Biomed Res Int. 2017;2017:9378325-9. https://doi.org/10.1155/2017/9378325.

2. Albrektsson T, Zarb G, Worthington P, Eriksson AR. The long-term efficacy of currently used dental implants: a review and proposed criteria of success. Int J Oral Maxillofac Implants. 1986;1(1):11-25.

3. Attia S, Schaaf H, El Khassawna T, Malhan D, Mausbach K, Howaldt HP, et al. Oral rehabilitation of hypodontia patients using an endosseous dental implant: functional and aesthetic results. J Clin Med. 2019;8(10). https://doi. org/10.3390/jcm8101687.

4. Becelli R, Morello R, Renzi G, Dominici C. Treatment of oligodontia with endo-osseous fixtures: experience in eight consecutive patients at the end of dental growth. J Craniofac Surg. 2007;18(6):1327-30. https://doi.org/10.1 097/scs.0b013e3180a772ff.

5. Brägger U, Aeschlimann S, Bürgin W, Hämmerle CHF, Lang NP. Biological and technical complications and failures with fixed partial dentures (FPD) on implants and teeth after four to five years of function. Clin Oral Implants Res. 2001;12(1):26-34.

6. Buser D, Weber HP, Lang NP. Tissue integration of non-submerged implants. I-year results of a prospective study with 100 ITI hollow-cylinder and hollow-screw implants. Clin Oral Implants Res. 1990;1(1):33-40.

7. Cordaro L, Ercoli C, Rossini C, Torsello F, Feng C. Retrospective evaluation of complete-arch fixed partial dentures connecting teeth and implant abutments in patients with normal and reduced periodontal support. J Prosthet Dent. 2005;94(4):313-20. https://doi.org/10.1016/j.prosdent.2005.08. 007

8. Costa AMG, Trevizan M, Matsumoto MAN, da Silva RAB, da Silva LAB, Horta $\mathrm{KC}$, et al. Association between tooth agenesis and skeletal malocclusions. J Oral Maxillofac Res. 2017:8(2):e3. https://doi.org/10.5037/jomr.2017.8203.

9. Creton M, Cune M, Verhoeven W, Muradin M, Wismeijer D, Meijer G. Implant treatment in patients with severe hypodontia: a retrospective evaluation. J Oral Maxillofac Surg. 2010;68(3):530-8. https://doi.org/10.1016/j.joms.2009.09. 012.

10. de Lima EA, dos Santos MB, Marchini L. Patients' expectations of and satisfaction with implant-supported fixed partial dentures and single crowns. Int J Prosthodont. 2012;25(5):484-90.

11. Donos N, Mardas N, Chadha V. Clinical outcomes of implants following lateral bone augmentation: systematic assessment of available options (barrier membranes, bone grafts, split osteotomy). J Clin Periodontol. 2008; 35(8 Suppl):173-202. https://doi.org/10.1111/j.1600-051X.2008.01269.x.

12. Emami E, de Souza RF, Kabawat M, Feine JS. The impact of edentulism on oral and general health. Int J Dent. 2013;2013:498305.

13. Farina R, Filippi M, Brazzioli J, Tomasi C, Trombelli L. Bleeding on probing around dental implants: a retrospective study of associated factors. J Clin Periodontol. 2017:44(1):115-22. https://doi.org/10.1111/jcpe.12647.

14. Filius MA, Cune MS, Raghoebar GM, Vissink A, Visser A. Prosthetic treatment outcome in patients with severe hypodontia: a systematic review. J Oral Rehabil. 2016;43(5):373-87. https://doi.org/10.1111/joor.12384.

15. Filius MAP, Cune MS, Koopmans PC, Vissink A, Raghoebar GM, Visser A. Dental implants with fixed prosthodontics in oligodontia: a retrospective cohort study with a follow-up of up to 25 years. J Prosthet Dent. 2018; 120(4):506-12. https://doi.org/10.1016/j.prosdent.2017.12.009.

16. Gaviria L, Salcido JP, Guda T, Ong JL. Current trends in dental implants. J Korean Assoc Oral Maxillofac Surg. 2014;40(2):50-60. https://doi.org/10.5125/ jkaoms.2014.40.2.50.

17. Heuberer S, Dvorak G, Mayer C, Watzek G, Zechner W. Dental implants are a viable alternative for compensating oligodontia in adolescents. Clin Oral Implants Res. 2015;26(4):e22-7. https://doi.org/10.1111/clr.12323.

18. Heuberer S, Dvorak G, Zauza K, Watzek G. The use of onplants and implants in children with severe oligodontia: a retrospective evaluation. Clin Oral
Implants Res. 2012;23(7):827-31. https://doi.org/10.1111/j.1600-0501.2011. 02226.x

19. Jonker BP, Wolvius EB, van der Tas JT, Pijpe J. The effect of resorbable membranes on one-stage ridge augmentation in anterior single-tooth replacement: a randomized, controlled clinical trial. Clin Oral Implants Res. 2018:29(2):235-47. https://doi.org/10.1111/clr.13106.

20. Karoussis IK, Muller S, Salvi GE, Heitz-Mayfield L, Bragger U, Lang NP. Association between periodontal and peri-implant conditions: a 10-year prospective study. Clin Oral Implants Res. 2004;15(1):1-7. https://doi.org/1 0.1111/j.1600-0501.2004.00982.x.

21. Karoussis IK, Salvi GE, Heitz-Mayfield LJ, Bragger U, Hammerle CH, Lang NP. Long-term implant prognosis in patients with and without a history of chronic periodontitis: a 10-year prospective cohort study of the ITI dental implant system. Clin Oral Implants Res. 2003;14(3):329-39. https://doi.org/1 0.1034/j.1600-0501.000.00934.x

22. Kassebaum NJ, Bernabe E, Dahiya M, Bhandari B, Murray CJ, Marcenes W. Global burden of severe tooth loss: a systematic review and meta-analysis. J Dent Res. 2014;93(7 Suppl):20S-8S. https://doi.org/10.1177/002203451453 7828 .

23. Kim KK, Sung HM. Outcomes of dental implant treatment in patients with generalized aggressive periodontitis: a systematic review. J Adv Prosthodont. 2012;4(4):210-7. https://doi.org/10.4047/jap.2012.4.4.210.

24. Leonhardt A, Grondahl K, Bergstrom C, Lekholm U. Long-term follow-up of osseointegrated titanium implants using clinical, radiographic and microbiological parameters. Clin Oral Implants Res. 2002;13(2):127-32. https://doi.org/10.1034/j.1600-0501.2002.130202.x.

25. Mengel R, Flores-de-Jacoby L. Implants in patients treated for generalized aggressive and chronic periodontitis: a 3-year prospective longitudinal study. J Periodontol. 2005a;76(4):534-43. https://doi.org/10.1902/jop.2005. 76.4.534.

26. Mengel R, Flores-de-Jacoby L. Implants in regenerated bone in patients treated for generalized aggressive periodontitis: a prospective longitudinal study. Int J Periodontics Restorative Dent. 2005b;25(4):331-41.

27. Mengel R, Heim T, Thone-Muhling M. Mucositis, peri-implantitis, and survival and success rates of oxide-coated implants in patients treated for periodontitis 3- to 6-year results of a case-series study. Int J Implant Dent. 2017;3(1):48. https://doi.org/10.1186/s40729-017-0110-6.

28. Mombelli A, Lang NP. Clinical parameters for the evaluation of dental implants. Periodontol 2000. 1994;4(1):81-6.

29. Moraschini V, Poubel LA, Ferreira VF, Barboza Edos S. Evaluation of survival and success rates of dental implants reported in longitudinal studies with a follow-up period of at least 10 years: a systematic review. Int J Oral Maxillofac Surg. 2015;44(3):377-88. https://doi.org/10.1016/j.ijom.2014.10.023.

30. Moy PK, Medina D, Shetty V, Aghaloo TL. Dental implant failure rates and associated risk factors. Int J Oral Maxillofac Implants. 2005;20(4):569-77.

31. Raikar S, Talukdar P, Kumari S, Panda SK, Oommen VM, Prasad A. Factors affecting the survival rate of dental implants: a retrospective study. J Int Soc Prev Community Dent. 2017;7(6):351-5. https://doi.org/10.4103/jispcd.JISPCD_380_17.

32. Rakhshan V. Congenitally missing teeth (hypodontia): a review of the literature concerning the etiology, prevalence, risk factors, patterns and treatment. Dent Res J (Isfahan). 2015;12(1):1-13. https://doi.org/10.4103/1735-3327.150286.

33. Reich $E_{1}$ Hiller KA. Reasons for tooth extraction in the western states of Germany. Community Dent Oral Epidemiol. 1993;21(6):379-83. https://doi. org/10.1111/j.1600-0528.1993.tb01103.x.

34. Sakkas A, Schramm A, Winter K, Wilde F. Risk factors for post-operative complications after procedures for autologous bone augmentation from different donor sites. J Craniomaxillofac Surg. 2018;46(2):312-22. https://doi. org/10.1016/j.jcms.2017.11.016.

35. Schalk-van der Weide, Y. (1992). Oligodontia: a clinical, radiographic and genetic evaluation: Universiteit Utrecht, faculteit Geneeskunde.

36. Schalk-van der Weide Y, Beemer FA, Faber JA, Bosman F. Symptomatology of patients with oligodontia. J Oral Rehabil. 1994;21(3):247-61. https://doi. org/10.1111/j.1365-2842.1994.tb01141.x.

37. Silva Meza R. Radiographic assessment of congenitally missing teeth in orthodontic patients. Int J Paediatr Dent. 2003;13(2):112-6. https://doi.org/1 0.1046/j.1365-263X.2003.00436.X.

38. Topcu AO, Yamalik N, Guncu GN, Tozum TF, El H, Uysal S, et al. Implant-site related and patient-based factors with the potential to impact patients' satisfaction, quality of life measures and perceptions toward dental implant treatment. Implant Dent. 2017;26(4):581-91. https://doi.org/10.1097/ID. 0000000000000623 
39. Yap AK, Klineberg I. Dental implants in patients with ectodermal dysplasia and tooth agenesis: a critical review of the literature. Int J Prosthodont. 2009;22(3):268-76.

\section{Publisher's Note}

Springer Nature remains neutral with regard to jurisdictional claims in published maps and institutional affiliations.

Submit your manuscript to a SpringerOpen ${ }^{\mathcal{O}}$ journal and benefit from:

- Convenient online submission

Rigorous peer review

- Open access: articles freely available online

- High visibility within the field

- Retaining the copyright to your article

Submit your next manuscript at $\boldsymbol{\wedge}$ springeropen.com 